\title{
Lost in translation: investigating the ambiguity of availability cues in an online media space
}

\author{
R. HARR* and M. WIBERG \\ Department of Informatics, Umeå University, 90187 Umeå, Sweden
}

\begin{abstract}
In this paper we present a longitudinal study of an online media space addressing the question of how availability is managed in an interaction-intensive organization. We relied on three different data collection techniques and analysed our data in relation to three different work modes. During this study we participated in an online media space, for approximately six months making spot checks and observing the population from which ten subjects were selected for interviews. Our results show how techniques and strategies for availability management are developed and continuously adapted to a shared common ground. Further, our results show how having the communication channel open, and regulating availability on a social level instead of on a solely technical level, has the advantage of better coping with the ever-changing dynamics in group works. Finally, we show that there exists an ambiguity of availability cues in online media spaces that is smoothly handled by individuals.
\end{abstract}

Keywords: Availability management; Workplace awareness; Interruptions; Media space

\section{Introduction}

Many researchers (e.g. Gaver et al. 1992, Fish et al. 1993, Bly et al. 1993, Tang and Rua 1994, Tang et al. 1994, Bly et al. 1996, Handel and Herbsleb 2002, Isaacs et al. 2002) have been interested in how constant connectivity can be used to support workplace awareness (Want et al. 1992, Greenberg 1996), i.e. the ability to use technology to mediate what colleagues are doing in order to provide a better basis for collaboration.

The ambition to create a situation of constant connectivity in which it is possible to reach anyone, anytime and anywhere is, however, not unproblematic. The frequency of which we encounter discussions concerning the growth of information that working individuals have to deal with is higher today than ever before. Topics such as 'cognitive overload' (Fussel et al. 1996), 'information overload' (Farhoomand et al. 2002) and 'interaction overload' (Ljungberg and Sorensen 2000) are often discussed in media, and vast amounts of research have been dealing with these issues (e.g. Speier et al. 1997,
Hudson et al. 2002, Adamczyk and Bailey 2004, González and Mark 2004). Technology is often considered as a catalyst for this increase of information and interaction since technology allows several additional channels for information and interaction, which produces an increase in interruptions for the individual (Markels 1997).

Yet another factor that produces an increase in interruptions is the modern organizational form based upon a movement towards forms such as self-organizing teams and open workflows to better support the responsiveness, flexibility and global nature of business environments of today (Speier et al. 1997). Richness of interaction within an organization does, at the same time as it facilitates the work process (Kraut et al. 1988, O'Conaill and Frohlich 1995), also threatens it through increasing the amount of disruptive interruptions (Weick 1995, Perlow 1999). In combination, technology as a catalyst and the organizational form of today, produces a potential threat for the individual and for organizations since a substantial rise in interruptions has been shown to affect individual performance in a negative way (Burmistrov and Leonova 1997,

*Corresponding author. Email: Rikard.Harr@informatik.umu.se

Behaviour \& Information Technology

ISSN 0144-929X print/ISSN 1362-3001 online (c) 2008 Taylor \& Francis

http://www.tandf.co.uk/journals

DOI: $10.1080 / 01449290600874865$ 
Speier et al. 1997, Davenport and Beck 2001, Horvitz and Apacible 2003). Many forms of work consist of both individual cognitive activities, with a demand for long periods of uninterrupted time during which workers can concentrate, and also collaborative activities with a demand for periods of interaction with other workers. Synchronization of individual and collaborative activities is crucial for the effective time use for groups, such that members of the group do not interrupt each other when they are involved in individual aspects of their work (Perlow 1999). As a consequence of the increase in the number of communication channels for the individual, the movement towards new organizational forms and the increase in the amount of interruptions that follows, the issue of availability management becomes a focal concern (Baecker et al. 1995, Endler 1996, Hudson et al. 2002). Here, we define availability management as "the ways in which a person signals to other persons in the surrounding (including also online contacts) if he/she is open to communication or not'.

In past work, availability management has been addressed from both an explicit, as well as an implicit, availability management point of view. By explicit availability management we refer to design of various kinds of technical support that often equals the notion of availability with the notion of presence and enable a user to switch between different availability/presence modes or profiles (compare for instance the explicit switch between different modes of status such as 'away' or 'occupied' in early versions of ICQ $^{\circledR}$ (ICQ Inc. 1996-2006)) or to filter incoming calls or interruptions by the use of additional systems (Ljungberg 1999, Rodenstein et al. 1999, Milewski and Smith 2000), which is often forgotten once the period of potentially inappropriate interval of time has passed (Milewski and Smith 2000, Lai et al. 2003). This strategy of requiring additional actions from an attention-limited and cognitively-overloaded person may not be the best strategy, since notifications of incoming messages, even if ignored, are disruptive to task performance (Czerwinski et al. 2000a, 2000b, Cutrell et al. 2001). To equal availability with presence is also problematic since availability is a state of mind (whether an individual is receptive for communication or not) and presence concerns the question of whether an individual is reachable via synchronous communication channels or not (Begole et al. 2004).

There have, however, been inspiring attempts made to support individuals with tools for implicit availability management as well. Implicit availability management can be defined as 'the ways in which a person unconsciously signals to other persons in the surroundings (including also online contacts) if he/she is open to communication or not'. Two main strategies for supporting implicit availability management with information technology (IT) can be identified in previous research.
First there is the strategy of automated calculation of individual availability or presence based upon automated information gathering from different input sensors, for example, by the use of speech detectors (e.g. Hudson et al. 2003, Fogarty et al. 2004a, 2004b, 2005) or combinations of different sensors such as motion and sound detectors (e.g. Begole et al. 2004). There are also several examples of computer-based techniques that monitor a individual's mouse and keyboard activity and convert that activity into information concerning if the individual is present or not. This information is then made available for others as sounds (Lövestrand 1991, Cohen 1993, Greenberg 1996) and as icons whose colour and shape correspond with activity levels (Greenberg 1996, Wax 1996).

The second strategy concerns different kinds of office shares such as media spaces, (Root 1988, Abel 1990, Buxton and Moran. 1990, Heath and Luff. 1991, Mantei et al. 1991, Gaver et al. 1992, Bly et al. 1993), video glimpses (Tang et al. 1994b) and video snapshots (Dourish and Beloti 1992, Lee et al. 1997, Johnson and Greenberg 1999). All of these are examples of technologies that enable individuals to determine the availability of others based upon the awareness information presented through ongoing audio/video transmission, glimpses or snapshots.

Even though these attempts to manage availability implicitly have proved to be successful, there are several reasons for conducting further empirical studies of which we will mention three. First, several of these studies have been conducted as experiments (Lantz 1986, Gaver et al. 1992, Johnson and Greenberg 1999) and have not focused upon availability management in real-life work settings. Johnson and Greenberg (1999), for example, conduct an experiment where participants estimate the availability of others based upon video snapshots that excludes the asynchronous aspects of awareness so vital in a real work setting. Second, several of the conducted studies took place over a decade ago with technological limitations that hopefully to some degree have been dealt with in modern systems (Lantz 1986, Root 1988, Mantei et al. 1991). The third reason is that several previous studies have been conducted upon use of prototype versions of media spaces instead of upon media spaces that are used in actual work settings and that have been used for an extended period of time (Lantz 1986, Mantei et al. 1991, Dourish and Bly. 1992, Tang et al. 1994). This brings us to our overall research question: How do individuals handle their availability in an interaction intensive organization of today with all the additional communication channels and an extended amount of interaction and information?

In order to investigate the question empirically, we conducted a long-term empirical study of a group of individuals in an interaction intensive organization that makes use of an online media space for collaboration and availability management. During our six-month study we 
used qualitative research methods for data gathering together with an analytical model of different work modes including: individual work, traditional co-located collective work and virtual collaboration, for analysis of data.

In the next section we delve into conducted research in the area of awareness and availability management before describing our analytical model of different work modes and switches between them in section three. In sections four and five we then introduce the empirical study followed by a discussion and our conclusions (sections six and seven) of how availability is managed in an interaction intensive organization.

\section{Background: awareness and availability management}

In this section, we present a more detailed description of research conducted in the areas of awareness and availability management.

\subsection{Awareness}

In previous research the term 'awareness' has been defined as 'an understanding of the activities of others, which provides a context for your own activity' (Dourish and Belotti 1992). Awareness is a concept that has for a long time received a lot of attention in the field of CSCW (computer-supported cooperative work) and groupware research (Dourish and Belotti 1992, Gutwin et al. 1996, Gutwin and Greenberg 1999). A multitude of studies has focused upon how collaborating individuals share information with each other in order to achieve awareness in groups and with the recent development of new communication technology such as cellular phones, instant messaging (IM) and online media spaces, this issue is more important today than ever before. CSCW researchers have, for example, focused upon general awareness (Gaver 1991, Bly et al. 1993), peripheral awareness (Gaver 1992, Bly et al. 1993), collaboration awareness (Lauwers et al. 1990), passive awareness (Dourish and Belotti 1992, Dourish and Bly. 1992), background awareness (Bly et al. 1993), mutual awareness (Benford et al. 1994, Schmidt 1994), reciprocal awareness (Fish et al. 1990, Schmidt 1994), workspace awareness (Gutwin 1997, Gutwin et al. 1999, Gutwin and Greenberg 2002) and workplace awareness (Handel and Herbsleb 2002, Isaacs et al. 2002).

Workplace awareness is the ability to use technology to mediate what colleagues are doing in order to provide a better basis for collaboration (Want et al. 1992, Greenberg 1996), for example, by reducing the search-time of colleagues in a workplace by the use of active badges (Want et al. 1992) or by using availability/presence feature of IM (Isaacs et al. 2002). In a physical workplace it is often taken for granted that one should be aware of one another in order to coordinate the collective activities in a satisfying way. According to Erickson et al. (2002) this is owing to our skill at using subtle cues to achieve awareness. When it comes to the coordination of distributed groups it becomes more difficult to achieve awareness (Cockburn et al. 1993, Gutwin and Greenberg 2002). There are, however, a number of technological support for distributed work but they are often insufficient, as the communication and coordination efforts via such systems often become clumsy and inefficient resulting in an increase in workload just to get the technology itself running (Kristoffersen 1997).

In a work setting where the participants share a physical environment it is quite easy to maintain a picture of what others are doing, for example, in an open-plan office. We mainly do this in an implicit way through, for example, auditory cues, peripheral vision and quick glances. In this way we can keep track of what goes on in our workplace. The visual field is greatly reduced in most groupware applications, and many of our mechanisms for gathering information in the physical setting (such as glancing) are obsolete since the required information may be absent from the visible part of the application. These mechanics of collaboration in a setting of physical proximity should be considered as unforced, spontaneous and natural. In a groupware workspace this is much harder to achieve. According to Gutwin and Greenberg (2002) this is because the input and output devices that are used only generate a fraction of what is generated in a face-toface workspace and the information that is generated when a user interacts with computational workspace is limited and groupware systems do not present the awareness information available to the system. Several observational studies have, however, demonstrated the usefulness of shared views of a workspace and of one another for collaboration around physical tasks, especially when compared with audio or textbased communication only (Fussel et al. 2003, Kraut et al. 2003, Gergle et al. 2004a). Gergle et al. (2004b) showed that pairs with a shared workspace more seldom verified their actions explicitly through speech and rather relied upon visual information to provide others with the necessary coordinative and communicative tools.

In order to support awareness, one should see to it that information leaves the scene of work and that one's colleagues receive the information. The possibility to be aware of the actions of one's colleagues is greater, the more information one receives. There is, however, a flipside on that coin: the more information we receive from others, the greater the risk that the information will disturb our normal work (Hollan et al. 2000).

\subsection{Availability management}

In an interaction intensive organization the opportunity of being always online also means that the issue of availability management (Endler 1996, Hudson et al. 2002) becomes a focal concern. Here, we define availability management as 'the ways in which a person signals to other persons in the 
surroundings (including also online contacts) if he/she is open to communication or not'. In previous research, availability management has mainly been addressed from an explicit availability management point of view. By explicit availability management we refer to design of various kinds of technical support that enable a user to switch between different availability modes or profiles. In this section we describe explicit as well as implicit approaches for availability management in some detail.

2.2.1 The explicit view/approach. An increase in channels for communication, the multi-threaded nature of individual and collective work and a situation characterized by constant connectivity calls for management of one's availability. An additional channel also means additional interruptions, which affects the possibilities for individuals to get their individual work done. The interrupted work environment is considered as commonplace for the knowledge worker (Speier et al. 1997). In the physical workplace there exist both implicit and explicit methods for managing one's availability, for example, talking to someone on the phone is an act that implicitly signals a reduced availability in a physical workplace. The primary objective is to talk on the phone and as a consequence a reduced availability is signalled to others in the same workplace (if they are aware of the conversation). Explicit availability management can be defined as 'the ways in which a person consciously signals to other persons in the surroundings (including also online contacts) if he/she is open to communication or not'. When, for example, closing the door, the primary objective is normally to signal a will to be left alone, hence an explicit signal of a reduced level of availability.

When it comes to availability management in an office of today there are several additional channels owing to connection to the internet and equipment such as various tools to support communication including e.g. hardware for voice and video communication (microphone, speakers and web cameras) and software (email clients, instant messaging clients, chat client, or more advanced audio/ video conferencing systems). When reviewing previous research conducted in this area it seems obvious that the way in which availability has been managed in computermediated communication applications differ from the way that availability is managed in the physical workplace. When it comes to availability management in collocated settings, both explicit (e.g. Hudson et al. 2002) as well as implicit strategies have been documented (e.g. Argyle, 1988). In computer mediated work settings, the explicit approach is typically applied (Ljungberg 1999, Milewski et al. 2000, Wiberg 2002) (see figure 1).

According to Ljungberg (1999), communication technologies presume availability to be binary. Users want to be available or they do not. According to certain studies (Ljungberg 1996, Ljungberg and Sorensen. 1996) this assumption is not a valid one. Instead people want to be constantly available but never for all sorts of communication. Many communication technologies do not support this human need, instead they often force users to switch on and off the communication device (Ljungberg 1999, Begole et al. 2004, Fogarty et al. 2005). Accordingly, two kinds of problems arise: appropriate communication is missed when the device is turned off, and when the device is turned on inappropriate communication is received.

Begole et al. (2004) refer to a number of proactive availability management strategies. One strategy for the recipient is to screen incoming calls and choose not to answer certain calls based upon caller-identification. Since telephones do not present information for an initiator whether the recipient is present or not there is always a possibility for the recipient to avoid unwanted interaction by 'plausible deniability' (Nardi et al. 2000), i.e. by claiming that he or she was not present when the phone rang. According to Nardi et al. (2000), this is also possible when it comes to IM, which contradicts with Begole et al. (2004) who claim that claiming plausible deniability when it comes to IM is somewhat problematic since the recipient's presence is known for the initiator. According to Begole et al. (2004) avoiding unwanted interaction over IM is as hard as it is to ignore someone waiting at your door, and screening does not really prevent unwanted interruptions since notifications of incoming messages, even if ignored, is disruptive to task performance (Czerwinski et al. 2000a, 2000b, Cutrell et al. 2001). Begole et al. (2004) also refer to another technique found in most IM systems that allows individuals to set their status and add some textual explanation. Even though this technique is used by many users there is a large portion that choose not to so and others that do it variably. The problem that Begole et al. (2004) identify in these proactive strategies is that, even though they have the potential to reduce unwanted interruptions, they might also reduce the amount of desired interruptions. Another problem with this approach is that it is sometimes difficult for a user to anticipate when he or she will be unavailable and once available the user might forget to unblock calls or might not take the action to block incoming calls when he or she is busy.

Ljungberg (1999) presents a prototype that realizes another approach. 'The Interaction Manager' enables the initiator and the recipient to negotiate if and how the interaction is going to take place. What the Interaction Manager, other prototypes and existing systems have in common is that they all demand an explicit act from the interactants to manage availability. This strategy of requiring additional actions from an attention-limited and cognitively-overloaded person may not be the best strategy to handle availability.

2.2.2 The implicit view/approach. Even though most attempts to support availability management for individuals in 
interaction intensive groups have been through explicit approaches, there have also been some attempts to use implicit approaches (e.g. Hudson et al. 2003, Begole et al. 2004, Fogarty et al. 2004a, 2004b, 2005). Implicit availability management can be defined as 'the ways in which a person unconsciously signals to other persons in the surroundings (including also online contacts) if he/she is open to communication or not'.

As mentioned in section 1, a review of previous work related to the issue of implicit availability management shows two main strategies for doing so. The first strategy is to rely on automated calculation of individual availability or presence based upon sensor-gathered information. The second strategy is to enable individuals to determine the availability of others based upon the awareness information presented through ongoing audio/video transmission, glimpses or snapshots.

The first strategy is, for example, used in several IM systems that indicate the elapsed time since a user last used the device; recent use implies that the user is nearby. Kakihara et al. (2004) state that this is not always a correct assumption since inactivity could be the result of the user talking to someone or reading. In relation to this Begole et al. (2004) conclude that users of electronic communication do not often have the necessary cues for negotiating contact as they do have in a face-to-face setting. Further on, they also present an alternative to the proactive approach that includes providing the initiator with the context information that is needed for making a judgement of the availability of the recipient, as in a face-to-face setting. In doing so Begole et al. (2004) present a prototype system called 'LilSys', which makes use of physical sensors, such as motion and sound detectors, as well as mouse and keyboard activity monitors. They also added a timer that enables users to override the system and set the user's status to the maximum unavailability level. Lilsys was integrated with the Awarenex system (Tang et al. 2001) and did therefore inherit device and calendar information from that system. When sensors change state the presence of the user is assessed through combinational data from sound, motion detector, keyboard/mouse and phone activity. Lilsys also assess unavailability by combining sensors for door, sound and phone. The inference is then displayed in the Awarenex contact list through the use of traffic-sign-inspired colour symbols; neutral for no inference, a yellow diamond for possibly unavailable and a red-bordered sign for probably unavailable. Their results indicates no less frequency of interruptions even though the LilSys enables a unavailability assessment, but in several cases the interruptions were tempered by acknowledging that the recipients were considered as being less available.

Another attempt to remedy the interruption problem through automatic gathering and calculations based upon awareness information was done by Fogarty et al. (2004b).
They present MyVine, a client that integrates instant messaging, phone and email communication channels with information received via sensors about the availability and context of colleagues. MyVine makes use of information gathered via speech detection, computer activity, location information and calendar information to create a model of the availability of an individual. The client shares availability and context with the belief that people will respect if a colleague is indicated as unavailable, but their results showed that it did not work this way, instead participants used the information as an indication of presence and not availability.

The second strategy, allowing individuals to manage availability through different office share systems, have resulted in attempts to use Media Spaces as a tool for availability management and awareness indication. Through the use of desktop video cameras the whereabouts of individuals are shared with others through continuous video/audio channels (Abel 1990, Mantei et al. 1991, Bly et al. 1993). There are also examples of systems that promote the sharing of short video glimpses, which allow fellow workers to glance into offices of his or her colleagues as when walking down the hallway (Tang et al. 1994). There are also examples of systems that provide a user with still images of other people's offices in order to support awareness and availability management. Individuals do often display these snapshots on their screen and glance at them from time to time (Dourish and Bly 1992, Lee et al. 1997).

Even though these attempts to support implicitly availability management have been proved successful on a prototype level of analysis, there are, as stated above, several reasons for conducting further empirical and longterm studies on this issue in real-world settings. This brings us back to our overall research question: How do individuals handle their availability in an interaction intensive organization of today with all the additional communication channels and an extended amount of interaction and information? To address this research question on a more detailed level of analysis we have conducted an empirical study of a real work setting which spans over three different work modes and switches between these different modes.

\section{Research scope: three different work modes and switches in between}

Very much of what we do in our work life is individual work in front of a single computer. We carry out tasks, fill in forms, report the workday or formulate our thoughts. All this work is easier to do if working alone, without interruptions from others. The individual work setting lets us take advantage of our reflective mode of cognition (Norman and Dunaeff 1993) and it enables us to 
concentrate and focus on a specific task at hand. Another important component of the modern workplace is that we are dependent on what others do to keep our own work going, and vice versa. Several workplace studies (e.g. Whittaker et al. 1994, 2004) show that working together, especially if being in close vicinity of each other, is of great importance for developing new ideas, for sharing informal and tacit knowledge, for coordinating activities and for dealing with everyday problem solving. Yet another important part of the modern workplace is that it typically also includes online colleagues supported by various kinds of interaction technologies including, for example, email, IM applications, chat rooms, shared project spaces and online media spaces. These new channels for interaction enable collaboration in terms of 'networking' (Ljungberg 1997), 'telework' (Dix and Beale 1996) or 'virtual collaboration' (Rutkowski et al. 2002). All these techniques are developed to enable us to work together as if we were at the same place by supporting awareness, and various kinds of both synchronous and asynchronous channels for text-, voice- and video-based communication.

One thing that is interesting to notice is the frequent switches between these three different work modes, i.e. individual work, traditional co-located collective work and virtual collaboration that the modern worker is involved in. During a workday a single worker enters and leaves these three modes all the time and might spend just a couple of minutes of his/her time in one of these work modes before switching to another session. In terms of this switching behaviour, modern work is highly dynamic and filled with interruptions (O'Connail and Frohlich 1995, González and Mark 2004). Some researchers in the field (e.g. Rouncefield 1994, Speier et al. 1997, Burmistrov et al. 1997) have in fact argued that modern work might best be described as a work with constant interruptions. As an example, in previous work studies of mobile professionals the participants were interrupted approximately four times every hour and spent approximately $10 \mathrm{~min}$ of every hour in an interruption (O'Connail and Frohlich 1995).
Given a situation, as the one described above, of constant switching between different work modes, participation in parallel work activities and dependence of awareness information for successful coordination of work, interruptions need to be controlled. As a consequence, the importance of being able to communicate to other colleagues if being available for interaction or not, i.e. an issue of 'availability management' (e.g. Hudson et al. 2002, Wiberg 2002, Wiberg and Whittaker 2005) becomes a focal concern. In fact, we need further studies of how individuals handle their availability in modern interaction intensive organizations with all the additional communication channels and an extended amount of interaction and information.

While previous research has focused on both technological and social aspects of availability management from the perspective of switches between individual work and collective work in co-located work settings (e.g. Hudson et al. 2002), and analysed this according to availability management, there is still some work to do on mediated work i.e. the switches between individual work, co-located collective work and virtual collaboration.

Motivated by this, our primary research focus is on the development, adoption and use of availability management strategies in an online media space. To address our overall research question, as outlined in section one, we focus upon how individuals, in an online media space, display whether they are available for interaction or not in relation to individual and co-located collective work.

In the next section we introduce the empirical study in which we have focused upon availability management in an online media space called the e-corridor (i.e. a primary focus on virtual collaboration). Our primary focus is thus on identifying different ways in which people manage their availability, implicitly and explicitly, through strategies as those previously reported in the literature concerning colocated collective work. These previous reports include e.g. different ways in which people use physical objects in their everyday work environment to regulate their availability, including e.g. spatial layout of stacks of books and papers

\begin{tabular}{l|l|l} 
& \multicolumn{1}{|c|}{ Explicit } & \multicolumn{1}{c}{ Implicit } \\
\hline Collocated & $\begin{array}{l}\text { The door is opened/closed } \\
\text { (e.g. Hudson } \text { et al., 2002) }\end{array}$ & $\begin{array}{l}\text { Body language } \\
\text { (e.g. Argyle, 1988) }\end{array}$ \\
\hline Mediated & $\begin{array}{l}\text { Turning on/off } \\
\text { communication media } \\
\text { (e.g. Ljungberg, 1999) }\end{array}$ & $\begin{array}{l}\text { Need for further } \\
\text { studies }\end{array}$
\end{tabular}

Figure 1. Overview of strategies for explicit and implicit availability management in collocated and computer mediated work settings. 
(Beyer and Holtzblatt 1998) as well as the use of the office door to signal their availability status (Buxton 1997, Kristoffersen and Ljunberg 1999).

\section{Empirical study}

In this section we present our long-term empirical study of availability management in an online media space called mPro. In this study we were interested in the nature of availability management in a real-life setting and our research approach was of a qualitative nature since depth rather than generalizations were sought for. The overall research question we have explored is 'how do individuals manage availability in an online media space'. We introduce this section with a description of the research site and the online media space that we have studied, followed by a description of our actual method and data gathering techniques.

\subsection{Research site}

Organization Alpha is located in the city of Luleå in northern Sweden, approximately $900 \mathrm{~km}$ north of Stockholm. Alpha was founded in 1995 and is currently the workplace for 16 individuals (14 males and 2 females). Alpha is a research and educational organization and in 1998, Alpha created the company Marratech AB that develops software for real-time interaction over the Internet. An example of software that the company has developed is the Marratech Pro system. The organizational form of Alpha is characterized by self-organizing teams and open workflows and is as a consequence dependent on rich and extensive interaction for its activities. The research work conducted at Alpha is lead by several project leaders and arranged in a number of different projects forming a network of more or less coupled individuals and groups since a project leader or a project worker often participates in several parallel projects. In this organizational network of frequently interacting individuals a core of tight-knit individuals with a shared history and often-shared goals has evolved. Many projects do also involve members from other organizations and these are often invited to participate in the e-corridor, at least as long as the project is running and sometimes longer. For this reason, the population of the e-corridor exceeds the number of individuals working at Alpha.

\subsection{The mPro system and the e-corridor:an online media space}

Marratech Pro (mPro) is a groupware that is installed on the desktop or laptop computer in order to get access to a group work environment with ability to communicate, share documents and information. The fact that the system is installed on the desktop computer reduces the behavioural cost of gaining access to the technology, which is in line with the conclusions drawn from the VideoWindow work at Bellcore (Fish et al. 1990). mPro supports textual and audio communication as well as transmitting and receiving video. In order to use these features a user need specific hardware such as a web cam (for video sending), a headset or microphone and loudspeakers (for audio sending and receiving) (as shown in figure 2).

The client is free and can be downloaded from Marratech's homepage. Once the client is downloaded and installed and the desired hardware is functional groups can 'meet' each other in specific virtual sessions. These are the features that the system provides (see figure 3):

1. Shared whiteboard. In this field groups can display and share different documents, images and drawings. It is also possible to use telepointers, mark up pens, text typing, free hand drawing and other tools and symbols.

2. Audio. This feature provides the user with the possibility to communicate with the whole group or with individuals. In order to communicate via audio to a specific group member in a private conversation it is mandatory to first activate the private chat window.

3. Chat. There is a feature for public chat and another for private chat. In the public chat all group members are able to view and read a group member's written contribution. It is also possible to paste a uniform resource locator (URL) or an email address,

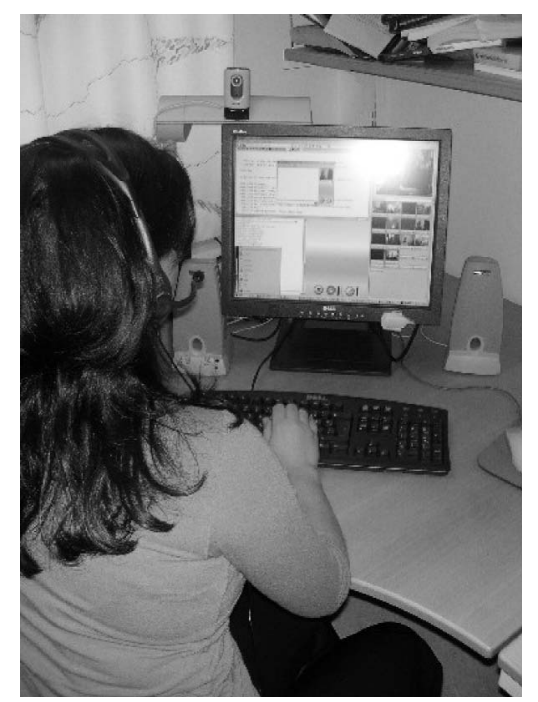

Figure 2. A participant in the e-corridor. Note the applied headset, and the web cam placed in front of the computer screen. 


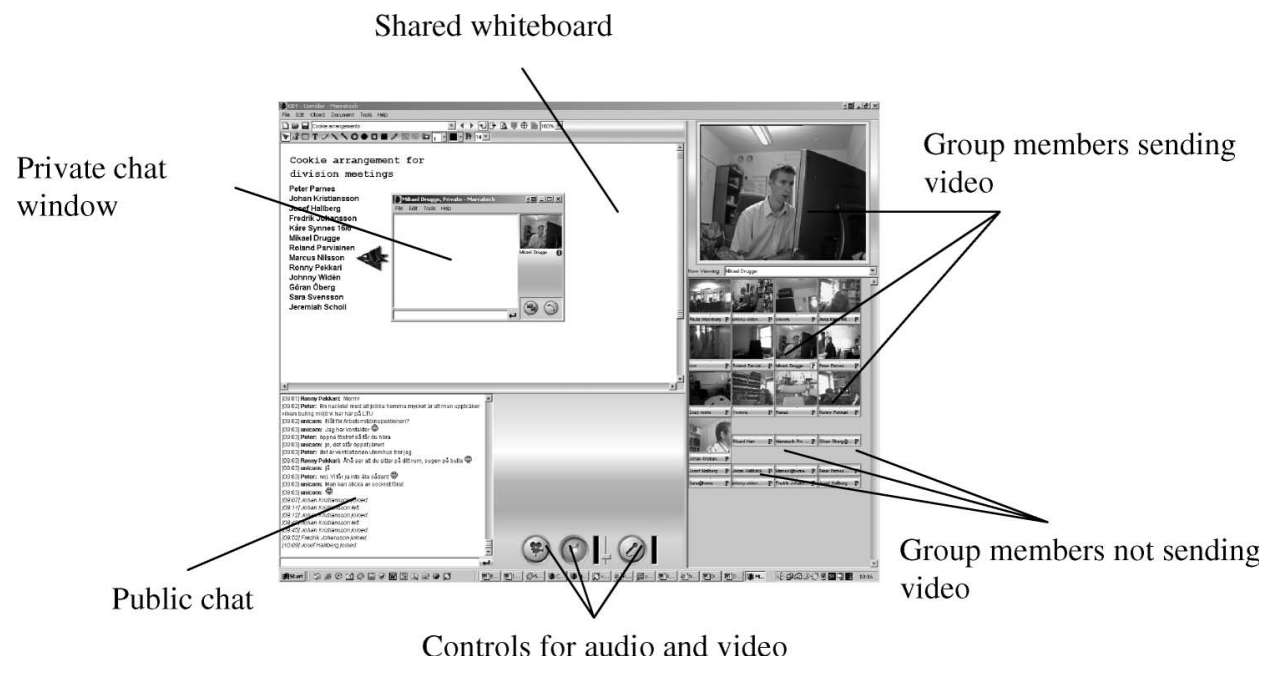

Figure 3. Features of the mPro system presented in a screenshot of the system interface.

for example. The private chat windows pops up when the name of a certain participant is clicked upon, independently whether they send video or not. The private chat allows the user to communicate with a certain group member in private, without demanding focus from other participants.

4. Video. This feature provides the user with a possibility to send and receive video from other users in real time. Many participants use this feature constantly but some prefer to use it only occasionally, for example, when private interaction is called for.

5. Recording and playback. It is also possible to record meetings for playback purposes. This feature is useful if someone is not able to attend a meeting or for documental purposes. Marratech Pro can record all media mentioned above, except private chat between other participants.

4.2.1 The e-corridor. Marratech $\mathrm{AB}$ has made the mPro client available for free on their web site and gain profit from leasing out virtual rooms to different customers. One of these virtual rooms is the e-corridor that has been used in organization Alpha since the mid 1990s. As a consequence, the system has been highly integrated into the everyday work in the organization. The e-corridor can easily be described as an mPro e-meeting that is ongoing. The participants of the e-corridor do often participate in other ad hoc mPro meetings as well, sometimes in parallel with their participation in the e-corridor. These time-limited ad hoc e-meetings take place in separate virtual rooms and are often of a more task-specific nature. The recording and playback feature is almost exclusively used for these task-specific meetings. In fact, we could not notice a single use of this feature in the e-corridor during our study. The virtual whiteboard is a feature that is used in different way in the e-corridor and in task-specific meetings. In taskspecific meetings the whiteboard is used to display the agenda of the meeting, cooperatively to write minutes during a meeting, to display presentation, images or sketches. In the e-corridor the whiteboard is normally not used, but sometimes the coffee list is displayed (a list that displays which employee who is going to bring buns and cakes for coffee on the weekly meeting). Sometimes a list of current events is displayed, with information such as who is abroad, upcoming visits and deadlines.

As the e-corridor is ongoing, people enter and leave the session with exception of those that always keep it running on their computers. Some do even keep it running from both their workplace and their homes at the same time. There are, however, also a number of participants that are best described as passive users in the sense that they do participate but very seldom contribute to the conversations taking place.

Once you join the session you are able to view transmitted video from the offices of others as well as the public chat and if there is anything written or posted on the virtual whiteboard. This means that, as a user, you are able to view the public chat, the whiteboard and peek into the offices of your colleagues without having to manipulate the system in any way. This in comparison to, for example, the RAVE system in which the system has to be manipulated in order to get a 'glance' of what a predefined individual is doing, or in order to 'sweep' the offices of several other predefined individuals (Mackay 1999). On one hand, the e-corridor could be characterized as a silent virtual room with very few oral conversations going on in public, on the other 
hand, the activity in the public chat is everything but 'silent'.

There are also private features available for interaction, for example, when establishing a private chat connection with another participant or a private audio connection. These conversations are not visible for others, which make them useful for handling errands that only concern the two involved individuals.

In total, the e-corridor supports group awareness through the video view, the public chat and the whiteboard. It does also support spontaneous and fast communication between two participants (the private chat and audio) or the group as a whole (for example when calling for a meeting).

The population of the e-corridor, as mentioned above, consists of more or less distributed employees from organization Alpha, other related organizations and peripheral partners.

\subsection{Method}

During our study we used three different data collection techniques: participatory observations, data logging and qualitative interviews.

4.3.1 Participatory observations. Our empirical study took off with participatory observations that spanned a period of six months. During this period we participated in the virtual e-corridor and regularly participated in the conversations taking place in the public chat as members of the community. We also participated in private chat and private audio-based conversations. Since the activity in the e-corridor is of a 'bursty' nature and since private conversation between other participants are not visible for an observer our observations should be characterized as frequent spot checks. During these spot checks notes on behaviour were taken and provided valuable input for the structuring of the follow-up interviews and the selection of respondents. It also enabled us to develop a deeper understanding of what it means to be a participant of this virtual environment. All participants in the e-corridor were aware of our presence and the purpose of our study. The total population of participants in the e-corridor consists of 25-30 individuals from different organizations, ranging from project leaders, project workers to administrators. The reason behind the imprecise number is the irregular participation in the e-corridor of several individuals.

4.3.2 Data logging. A history collection tool (Parviainen and Parnes 2004) enabled us to, for one month, collect usage data from the e-corridor, which was used for identification of those individuals that were most active in the public chat. During that month, a number of 3197 contributions were made by a total of 19 active individuals in the public chat. The data logs were used for the selection of respondents for the qualitative interviews. The actual selection was based upon professional roles, attendance, and activity level in the e-corridor. We first divided the total population into groups of professional roles and then selected the individuals that most frequently appeared in the e-corridor and also those that were most active in the public chat (for a further description of the different features of the mPro system, see section 4.2). The result of the activity log is presented in table 1 .

4.3.3 Qualitative interviews. Of the total population of active participants in the e-corridor a number of ten subjects from different work categories were selected for interviews. Eight of the interviews were conducted during the second month and two more during the forth month, and as mentioned above, the selection of respondents was based upon the following three parameters: activity in the chat, attendance and professional role in the organization. The aim of the interviews was to obtain the users views of how they regulate their availability in organization Alpha through their use of the e-corridor. Each interview lasted between 45 and 90 min and was taped or recorded (the recording feature of the mPro system was used in two of the interviews), the interviews were later transcribed for analysis. Two of the interviews were conducted via the audio/video features available in the mPro system, and the others were conducted at the actual research site. The analysis of the gathered data was based upon the different work modes described in section 3. A description of which data that was collected with each data collection technique is summarized in table 2.

\section{Results: the ambiguity of availability cues in an online media space}

In this section we present the results from our empirical study. To make the distinction clear between different

Table 1 . The results of the activity log based upon number of contributions in the public chat.

\begin{tabular}{lcc}
\hline Professional role & $\begin{array}{c}\text { Amount of } \\
\text { contributions }\end{array}$ & $\begin{array}{c}\text { Percentage of } \\
\text { all contributions }\end{array}$ \\
\hline Project leader A & 96 & $3.0 \%$ \\
Project leader B & 974 & $30.4 \%$ \\
Project leader C & 123 & $3.8 \%$ \\
Project leader D & 449 & $14.0 \%$ \\
Project worker A & 23 & $0.7 \%$ \\
Project worker B & 192 & $6.0 \%$ \\
Project worker C & 199 & $6.2 \%$ \\
Project worker D & 123 & $3.8 \%$ \\
Administrative A & 7 & $0.2 \%$ \\
Administrative B & 78 & $2.4 \%$ \\
Total & $2264(3197)$ & $70.5 \%(99.7 \%)$ \\
\hline
\end{tabular}


Table 2. The relation between data collection techniques and type of data collected.

\begin{tabular}{|c|c|}
\hline Data collection techniques & Type of data gathered \\
\hline Participatory observations & $\begin{array}{l}\text { Notes on behaviour related to } \\
\text { availability management of } \\
\text { participants and the community } \\
\text { of participants in the e-corridor }\end{array}$ \\
\hline Data logging & $\begin{array}{l}\text { Quantitative data of activity levels } \\
\text { of individuals during one month }\end{array}$ \\
\hline Qualitative interviews & $\begin{array}{l}\text { In-depth data concerning availability } \\
\text { management of individuals and the } \\
\text { community of participants in the } \\
\text { e-corridor }\end{array}$ \\
\hline
\end{tabular}

aspects of availability management we present our results according to the two following categorizes: Explicit and implicit availability management in the e-corridor. However, as our results will show there exists an ambiguity of social cues between these categories when it comes to availability management.

The participants of the e-corridor are all almost exclusively related to the activities of Alpha, sometimes guests are invited or old colleagues join the session for a shorter period of time, but in total, very few outer contacts are invited for an extended period of time to the e-corridor. Most users participate from their offices but it is quite common that some users participate from home. There were in fact some users that almost constantly participate from home and it sometimes happened that a user joined the e-corridor located in different temporary settings such as from a hotel or an airport. During our one-month activity log study, one participant participated from a oneweek conference in Japan.

Not all web cameras are located inside an office, there are also cameras placed in the hallway outside the offices as well as in the coffee room. These cameras provide remote users with the possibility to participate in an informal coffee meeting or monitor the total activity in the physical corridor by monitoring the hallway.

It is worth mentioning the ways in which availability information is interpreted by participants of the e-corridor is based upon some general cues, but also upon knowledge of persons in combination with less general cues. One thing that is general is that a glance at the videowindow almost exclusively precedes an attempt to establish interaction.

\subsection{Explicit availability management in the e-corridor}

By explicit availability management we refer to the way an individual explicitly signal to other individuals in the surroundings if he/she is open to communication or not.
The participants of the e-corridor have developed some more or less general methods to signal theirs or read the availability of others based upon manipulation of the $\mathrm{mPro}$ system. To signal a high availability is done through full participation (audio, video), or at least as full as possible. To signal a reduced availability is realized by limiting the information that is sent to other participants and the most drastic method is to choose between participation and non-participation. According to several of our respondents, participants do this when, for example, working towards a deadline or preparing for a presentation. There are less drastic methods to explicitly signal a reduced availability as well, for example, if a user turns off his or her camera (but still participates in the session). The colleagues interpret a user who chooses not to send video from his or her office as less available than a colleague that do. One respondent said during the interview that, when the system recently had been implemented, he sometimes attached a post-it note in front of the camera with a message about his activities, for example, that he would return shortly or that he was absent for some time. Soon he stopped doing so as he experienced the procedure too static since, for instance, he actually had to be in the work place to change his explicitly displayed availability status.

A reduced level of information that is sent out from an office does not necessarily prevent others from contacting a person, but it does often change the way that the interaction is finally established. Several respondents said, during our interviews, that if someone is not sending video he or she is considered as occupied which often results in a choice of an alternative channel for communication, often an asynchronous channel which is considered as less demanding for the receiver since he or she can choose an appropriate time for dealing with it.

According to two respondents, another method for signalling a reduced level of availability is the act of directing the camera towards the wall. This could mean that the person has a visitor that does not want to appear on the screens of others or that the person is doing something that requires some degree of privacy. To turn the camera towards the wall definitely limits the availability information that is sent out, but it also enables the others to see whether the light is on or not, which is interpreted as a signal of presence or non-presence. Worth mentioning is that this does not occur very often and during our observations we could not identify even one example of this behaviour.

Several of the participants of the e-corridor work from home on a regular basis. Based upon our study, several participants of the e-corridor choose not to send video from home; this is not interpreted in the same way as when not sending video from work. There are two additional reasons for not sending video from home, besides signalling a 
reduced level of availability. First, some have limited bandwidth at home and sending video requires a lot of bandwidth. Second several participants avoid sending constant video from home owing to integrity aspects, not only for securing their own privacy but also for other family members. Those who choose not to send video from home for these two reasons are known in the community, which prevents a direct interpretation of a turned off camera to be a signal for reduced availability. In the graphical interface of mPro it is easy to see whether a person is sitting at home or at work and the availability signals are interpreted based upon that knowledge.

\subsection{Implicit availability management in the e-corridor}

On an everyday basis, availability management in the e-corridor is also often handled implicitly. This means that the availability of a person is determined by his or her everyday actions or by status of certain objects. This judgement of availability is based upon both synchronous information (e.g. current events such as watching someone talking on the phone) and asynchronous information (e.g. what have happened in the past, for example, to have seen someone leaving the office). This information is received via available communication channels. Synchronous information is often gathered via the public chat, but mostly via the video in which presence of a person is signalled and also the level of availability. Asynchronous information is received via a multitude of channels including channels outside of the e-corridor, but mostly via the e-corridor i.e. video and chat.

During our observations of the public chat we noticed several situations in which the availability of a certain individual was discussed based upon synchronous awareness information. In this excerpt project leader Karl can see that another project leader, Ronald, is participating from an unknown site and Karl wants to know from where. The excerpt illustrates how the site from which a person is participating in the e-corridor is decided based upon information gathered from the environment displayed in the video view. In the excerpts the actual time of each comment is provided in order to provide a feeling of the timeline of the conversation, the names of the involved actors have been altered in order to protect their integrity and the conversations have also been translated into English. We furthermore wanted to keep the sequence of comments intact (even if some are off topic) in order to provide a glimpse into the intertwined nature of the conversation in the public chat.

Excerpt 1: Locating a colleague based upon environmental information displayed in the video view.

15:51:47 Karl (project leader): Where is Ronald? 15:51:54 Piotr (project leader): The demo studio
15:52:01 Karl: Fun with students in the image [STUDENTS ARE VIEWED IN THE VIDEO TRANSMITTED FROM RONALD] 15:52:09 Karl: yes it is

15:52:15 Karl: strange view [THE CAMERA IS PRESENTING A RATHER UNCONVENTIONAL VIEW OF THE GROUP]

15:53:08 Karl: Piotr, I talked to Ivan from Krakow - but he was kind of weird :-)

15:53:57 Jerry (project leader): Ronald is sending from the demo studio. Looks like the sofas there. [JERRY HAVE MISSED THAT PIOTR HAVE ALREADY IDENTIFIED THE SITE FROM WHICH RONALD IS TRANSMITTING]

15:54:21 Jerry: as you have noticed already (-:

This excerpt illustrates how environmental information displayed in the video view enables Jerry to locate Ronald. It also shows how a colleague (Piotr) helps Karl to identify the site from which Ronald is participating. The reason for Karl to locate Ronald in this case was not primarily for establishment of interaction but rather out of curiosity. The information that Ronald is currently together with students in the demo studio might however be useful for determining his availability in a later stage as asynchronous information.

Three respondents mentioned during the interviews that the way that implicit signals are interpreted in order to determine the availability of others is sometimes dependent of knowledge of persons, but some signals are more general, for example, if someone is absent or present in their office, if the door is opened or closed, if the light is on or off, if the person is turned towards or away from the computer screen or if he or she is holding a phone to his ear.

5.2.1 Everyday objects as signals of availability. Everyday objects serve an important role when it comes to implicit availability management in the e-corridor. According to our respondents the availability information that is sent from an individual is highly dependent on the everyday use of physical objects such as the door, the headset, a document, a book or a phone.

As in the physical workplace an open door signals a higher level of availability than a closed one and a book in the lap of an individual is interpreted as a signal of reduced availability. These signs of availability are transcended from the physical world and are gathered and interpreted by other individuals in a rather sophisticated way. From the offices of some users it is possible to see whether their door is open or closed when they are away and this is interpreted, in combination with knowledge of person and asynchronous awareness information, as a cue whether they are going to stay away for long or if they are in the 
vicinity, a closed door signals a more permanent absence than an open door (see figure 4).

Participants in the e-corridor are often seen wearing headsets. According to our respondents and observational data, the way that this is interpreted when it comes to estimation of availability varies from person to person since people tend to use them in different situations. Often, an attached headset is considered as a signal that a person is participating in an e-meeting, but since some people also use headsets when listening to music the attached headset is not always interpreted as a signal communicating participation in an e-meeting. According to the observational data the availability of someone wearing a headset is determined based upon knowledge of person. Some respondents distinguish between when people have their microphone in front of their mouth and when it is not, as a cue whether they are listening to music or participating in an e-meeting, sometimes they may even interpret mouth movements as a signal of participation in an e-meeting and vice versa. We acknowledge that it would be possible to apply a technological solution for this vagueness of availability cues through the use of some sort of icon that indicates participation in a meeting or that an individual is listening to music. However, according to our respondents this situation of ambiguity seldom causes any problems, in fact, it might actually cause a positive side effect since an initiator of a conversation feels urged to approach the individual wearing a headset with caution, for example by sending a private chat message with a question whether interaction is appropriate or not.

We now present an excerpt from a longer conversation in the public chat between four individuals-Ronald, Karl, Jerry and Robert - showing how availability of a certain



Figure 4. An empty office signals a reduced level of availability but since the door is open (and the light is on) the availability is considered as higher than it would be with a closed door. individual is checked, individual availability cues (concerning the use of the headset) are discussed and humorous aspects of conversations are intertwined in the mPro chat.

Excerpt 2: Availability check, discussion of individual availability cues based upon use of objects (the headset) and humorous aspects of conversation.

14:07:56 Ronald (project leader): have a video tape would like to covert it to a CD who can help me?

14:08:05 Karl (project leader): johnny

14:08:22 Ronald: J O H N N Y can you?

14:08:41 Jerry (project leader): John is in a meeting

14:10:30 Ronald: Are you sure he might just have his headset attached

14:10:36 Jerry: [I AM] Sure

14:10:57 Ronald: Karl usually answers anyway :-)

14:11:47 Ronald: he [REFERRING TO KARL] answers even if he is not in the picture [SENDING VIDEO], I don't know who he does it :-)

14:12:26 Ronald: anyone knows where Martin is?

14:12:39 Karl: Martin nows :-)

14:12:43 Karl: +k [COMPLETING THE WORD KNOWS]

14:12:52 Karl: I can only send single video

14:13:00 Karl: So am participating in the board meeting right now

14:13:33 Ronald: Intended to bring Martin with me who never gets to participate on TV

14:13:40 Ronald: Program information Open entrance and technological base year Thursday 25 of March 2004 13 o'clock, room F531

14:13:53 Ronald: 1440 Media technology

14:48:57 Robert (project worker): Martin is participating in a $\mathrm{PhD}$ course right now in the e-house

This illustrates how the chat is used for quick questions and answers (Ronald is looking for someone who can help him in converting a video tape into a CD and he is also looking for Martin), how available John is for interaction when his headset is attached and how humorous comments are intertwined with other threads of conversation (Karl says that Martin knows where he is as a comment to Ronald's question). The excerpt also shows how an individual (Robert) who, until that moment, had not participated in the conversation tell Ronald where Martin is. When reviewing the conversation it is also easy to see how smoothly the public chat enables participants to develop and share their knowledge of person in cooperation with others. This cooperative sharing of knowledge of person is facilitated in the e-corridor due to the unobtrusive and extensive interaction that takes place in the public chat. This collaborative process is much more difficult to accomplish in related audio/video systems such as the 
CAVECAT system and the RAVE system since they do not provide the public chat feature (Mantei et al. 1991, Buxton and Moran 1990, Mackay 1999). In this excerpt it is established that Johnny can convert a video tape into a CD, that Karl always answers an incoming message, Karl is part of the board and that Martin is taking a PhD course. This is information that is more difficult to acquire in an audio/video only environment, such as the RAVE (Buxton and Moran 1990, Mackay 1999) or the Cruiser system (Fish et al. 1993), since these systems do not support public chat.

Another everyday object that signals a reduced level of availability is the phone. When a person is talking on the phone or just holding it, he or she is considered as less available. If a person is seen holding a telephone to his head, asynchronous communication channels are often selected or a synchronous channel with an accepted delay of the response. One of our respondents also commented that participants of the e-corridor are often very good at multi-tasking, which enables them to talk and chat at the same time.

5.2.2 Everyday actions as signals of availability. Most participants constantly send video from their offices (mostly while working but some keeps it running constantly, two respondents do so both from home and from work simultaneously) and participate in discussions that occur in the public chat. This means that other participants may observe his or her colleagues through the video view and read their contributions in the public chat throughout the day and create a picture of what is happening in the workplace and what each individual is doing. As stated by one respondent during an interview:

If you follow the discussion that take place, regardless if you take active part as a sender or receiver you do take part of it and get a better picture of what is happening and what people are doing. That is definitely an effect, you acquire a better understanding of what people are doing.

According to our respondents this gathering of information enables the participant to estimate the availability of another person and if interaction is wanted it could be initiated in an appropriate moment and with appropriate tools. As mentioned above this estimation is based upon explicit information and the use of physical objects as signals for availability, but it is also based upon the everyday actions of others. This information is considered as very important for availability management in the group and interpretation of the availability of another person is based upon both synchronous and asynchronous information, i.e. what is the person doing right now and what has he or she has been doing in a recent past. This feeling of what is going on is also acquired by monitoring the video window. For example, if a person is sitting in the office right now but has been moving in and out of the office in a recent past, but also upon the conversation that takes place in the public chat. Another example of how actions are interpreted as a signal of availability is when someone is sitting and reading or talking turned away from the computer screen. Accordingly, being turned away from the screen often signals a lower level of availability, for example, in the case when someone is turned away towards a visitor (see figure 5).

During one of the interviews a future respondent rescheduled the time for his interview through the mPro private chat since he noticed that the respondent that we were currently interviewing (we were not present in the video view) was acting in such a way that he signalled participation in a conversation that could be interpreted as an interview (or a similar conversation). Of course, he could not know for sure that this was the case but it turned out that he was right.

As this example shows, to be considered as busy does not necessarily mean that no incoming messages will be received but it will most likely affect the choice of communication channel for interaction and the expected response. At what time, how and through which channel a message is sent is not only based upon the estimated availability, but also upon several other aspects such as relation between sender and receiver, nature of the errand and knowledge of person.

\section{Discussion}

So, why do people participate in the e-corridor and enable others to interpret their availability based upon implicit signals instead of just turning on and off the technology? We believe that there are several possible answers to this question. First of all, a longitudinal use of an always-on communication channel like the e-corridor is good for

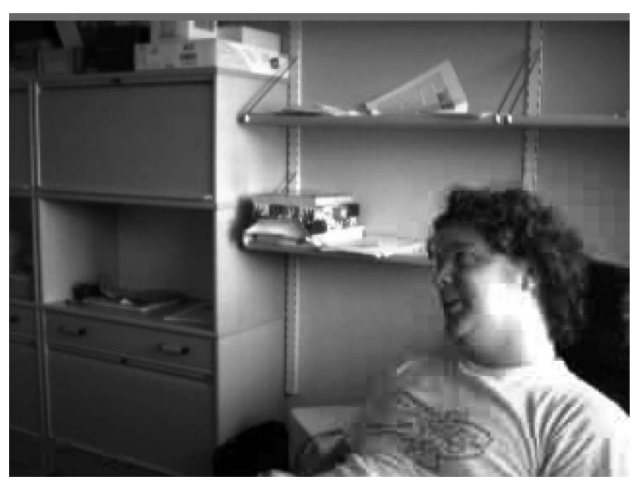

Figure 5. Being turned towards a visitor signals a lower level of availability to other participants in the e-corridor. 
developing and maintaining a sense of group belonging for highly distributed work groups. This is in line with what was assumed but not identified in a trial study by Fish et al. (1990) of the VideoWindow system at Bellcore. It also helps in developing and maintaining a high level of group awareness. Further, having the communication channel open and regulating availability on a social level instead of on a solely technical level has the advantage of better coping with the ever-changing dynamics in group works and being able to, in a lightweight manner, follow the dynamics of when a person is fully available or to busy to respond and every fine-graded level of availability within that spectrum.

The aim of the current paper was to explore availability management in an interaction intensive organization. This purpose was motivated by the frequent switches in between different work modes, i.e. individual work, traditional colocated collective work and virtual collaboration, that the modern worker are involved in. To address our overall research question, as outlined in section one, we focused upon how individual availability is managed, in an online media space, in relation to individual and co-located collective work. According to our results, the work that is conducted in these specific work modes are highly integrated and, as a result, it becomes very difficult to separate them from one another. In the mode of virtual collaboration, individual work as well as co-located collective work are often discussed and the other way around, as when Karl ask other participants in the public chat if they know the physical location of Ronald (excerpt 1). Based upon our results, this integration of different work modes and the frequent switches in between, are difficult to handle with an explicit availability management approach, instead an implicit approach that promotes a more fine-grained availability management should be applied for reducing the amount of disruptive interruptions for the individual.

The effects of interruptions upon individuals have been documented elsewhere (e.g. Speier et al. 1997, Davenport and Beck 2001, Horvitz and Apacible 2003). Speier et al. (1997), for example, focus upon task interruptions and information presentation on individual decision-making and acknowledge an increase in interruptions for the individual.

According to Perlow (1999) and others, interruptions occur since collaborating individuals are dependent upon rich and frequent interaction in order to do their job. Since the need for interaction is a natural part of collaboration it could be devastating for an organization to restrain the amount of interaction between collaborating individuals in order to prevent disruptions caused by interruptions. Instead measures should be taken to reduce the level of counterproductive interruptions, for example, by enabling implicit availability management in groups, or to reduce the negative effects caused by interruptions, for example, by allowing light-weight negotiations of when and how an incoming message is to be dealt with or by shortening the recovery time for the interrupted individual after an interruption.

When it comes to sharing awareness information between individuals in an organization the issues of integrity and privacy are often raised. This is a question that is highly relevant in most cases, but still a question that we have chosen not to deal with in this paper since integrity and privacy were not presented as important issues for the availability management processes in the e-corridor. There are several possible explanations for this.

1. It is important to understand that participation in the e-corridor is not compulsory among the employees of organization Alpha, an employee might choose not to participate at all in the virtual environment. Of course, this non-participation might, for example, complicate the introduction process or socialization process since a large part of the information that flows in the organization is easiest acquired in the e-corridor.

2. The core participants of the e-corridor are best described as a tight-knit team or at least as a tightknit network of project leaders, workers and administrative. This means that, as they interact with each other frequently and have done so for some time, they reach a point where they feel comfortable in sharing awareness information with each other.

3. As employees in organization Alpha have partly developed mPro it seems reasonable to believe that a culture to 'live as you preach' exists. At least, the organization should be characterized as an IT positive one, which might affect the way technology is embraced.

4. The mPro system provides several features that might be used for privacy and integrity protection. As reported in previous sections, it is quiet common that participants have their cameras turned off to some extent, or directed in an angle that delimits the awareness information being shared with others.

It is worth mentioning that since some of these explanations are more connected to the nature of organization Alpha than to the specific Media Space application, caution should be taken when introducing the application in another organization. We do however firmly believe that the adaptability of the application, and the adaptability of individuals, opens up for successful use in other contexts as well.

Since our study was of a longitudinal nature we were able to see how participants were introduced to the e-corridor 
and how they adapted to the community over time. One respondent, in the beginning of our six month study, used a flower placed in front of the camera as a Venetian blind for integrity and privacy reasons, he wanted to reduce the view of himself in the video view but with time he cut the flower down and in the end of our study the flower became almost impossible to see. He commented on this issue by saying that he felt more comfortable with the camera as time went by and that he eventually felt no need to filter the video stream sent from his office. Several respondents commented that they originally had some concerns when it came to constantly sending video from their office but all of them said that they became used to doing it after a while.

In the present paper we have focused upon how availability is managed in an online media space and we have shown that the estimated availability of a colleague provides the individual with important information before selecting an appropriate communication channel for establishment of interaction. However, according to our study decisions, how to approach a colleague is not solely based upon an estimation of the availability of a colleague, an estimation based upon both synchronous and asynchronous information, but also upon other factors such as the nature of the errand and knowledge of person. These are all aspects that enable individuals to deal with the ambiguity of availability cues and prevent misinterpretation and promote a smooth flow of communication. An important feature in the mPro system for the development of knowledge of person is the public chat. As mentioned in previous sections participants tend to monitor not only the video view on a regular basis but also the public chat in which most of our respondents are active on a regular basis. The public chat is a feature that was not available in most related systems such as the RAVE system (Buxton and Moran 1990, Mackay 1999), the CAVECAT system (Mantei et al. 1991) or the Cruiser system (Fish et al. 1993). One benefit of monitoring the public chat is that it enables participants to develop an extensive knowledge of persons based upon frequent chat interaction, even if not always participating actively. Another benefit of the public chat is that it is asynchronous and can be viewed at a later time, which prevents a situation in which the individual feels forced to interrupt their work in order to follow the ongoing communication flow.

To summarize, the public chat in the e-corridor constitutes an unobtrusive and continuous communication channel that enable the participants of the e-corridor to maintain an extensive communication flow without causing disruptive interruptions. This brings that the participants are able to follow and implicitly signal how theirs or others strategies for availability management are evolved and refined over time.
Since the e-corridor had been in use for some time when we started our study and since our study was of a longitudinal nature we were able to see an alteration when it comes to the perceived social relationships among those exposed to the technology. This increased social closeness, owing to extensive communication and virtual coexistence, which could not be identified in the VideoWindow work at Bellcore (Fish et al. 1990), is something that we consider to be very important for smooth availability management in virtual environments.

We acknowledge that individuals sometimes might become lost in translation and interpret availability cues in a wrong way, especially if the awareness information received from others is limited. This is something that could be prevented by system generated awareness information such as whether a headset is applied for listening to music or for participation in an e-meeting. However, we strongly believe that regulating availability on a social level instead of on a solely technical level has the advantage of better coping with the ever-changing dynamics in group works even if we acknowledge technical solutions for some aspects of sharing awareness information within groups.

The decision of how to approach a colleague based upon estimated availability is often a decision of 'how', and not a decision of 'if'. Some could argue that this would not lead to a reduced amount of interruption for the individual, and according to our study they are right. However, according to our respondents, the negative effects of interruptions vary from one communication channel to another, communication through asynchronous communication channels are considered as less disruptive since the receiver can choose an appropriate time for dealing with it. We see a danger in preventing interaction between individuals since rich and extensive communication is crucial for interactionintensive organizations. Instead we should strive for less disruptive interruptions and as mentioned above providing groups with technology that supports availability management on a social level instead of a solely technical level could help us to do so.

The relation between being present and/or being available is a delicate question that needs to be dealt with. Presence is normally used in today's communication systems to signify whether an individual can be reached via synchronous communication channels and is typically compared with device presence, determined by, for example, whether a mobile phone is in range or whether ICQ is on. Device presence is, however, not always the same as person presence since a device may be left online even if the person have left the scene (Begole et al. 2004). To be present is fundamental for being available, but it is possible to be present without being available since availability is also based upon whether an individual is receptive to communication or not (Kakihara et al. 2004). 
In the physical world as well as in the e-corridor, presence is not directly interpreted as being available, which our results have shown, a person can be present in his or her office but being interpreted as unavailable by others since he or she is talking on the phone, wearing his or her headset, reading or talking to a guest and as a consequence becomes assessed as non-receptive for communication. Most computer support for availability management is based upon explicit acts for signalling availability and the shortcomings of this approach have generated some attempts to manage availability implicitly through the use of different tools for measuring activity and calculating the availability of the individual (e.g. Hudson et al. 2003, Begole et al. 2004, Fogarty et al. 2004a, 2004b, 2005). The explicit approach fails for several reasons, for instance, people tend to forget to change their status when they go from one mode of availability to another and the actual manipulation of the availability tool calls for actions from the individual which should be seen as counterproductive since the initial problem was a disruptive level of interruptions and it does not seem as a good idea to add yet another. Attempts to remedy the availability problem by implicit strategies such as adding different tools for measuring activity and calculating the availability of the individual initially seems like a good idea but the results of those attempts are not very convincing. One reason for this could be that people do not trust the system to 'calculate' the availability of others for them, and as a consequence the displayed availability status is interpreted as presence status (Fogarty et al. 2004b). Another important aspect is the one that we are always available for interaction, but not for all kinds of interaction. By providing your colleagues with information of what you are doing you enable them to act accordingly, by providing them with nothing or perhaps by providing them with a three-graded scale will sometimes hinder wanted interaction and promote unwanted interaction. In the physical world we handle our signalling of availability through implicit signals and based upon our results this could also be done, at least to some extent, in a setting of virtual collaboration.

An often seen argument for regulating the amount of awareness information that is sent to others is that too much information will disturb their work. This is an argument that has to be taken seriously, but as long as the awareness information is of a peripheral kind and as long as the each individual can manage the specific information that they receive this should not be an insurmountable problem. For the participants in the e-corridor it is not.

\section{Conclusions}

In thecurrent paper we have presented an empirical study of availability management in an online media space called the e-corridor. While previous research in this area has mainly focused on the ways in which people use explicit availability management strategies to signal to others about their availability status, this paper has looked closely into the more implicit ways in which this personal availability status is signalled to others, and the relation between implicit and explicit availability management strategies in a real-life setting.

As a result of our empirical study we have been able to observe how techniques and strategies for implicit availability management are developed and maintained in the everyday working life in organization Alpha. Extensive virtual co-existence promotes the development of a common ground concerning personal implicit availability management strategies and techniques, which is beneficial for the flow of interaction within the organization and the prevention of disruptive interruptions. An observation of how people implicitly manage their availability in office shares is not novel but has in fact been noticed in previous studies. However, while most of these previous studies concern controlled experiments or small-scale, short-term studies of prototype systems, our study has served the important purpose of studying availability management in an online media space, which has been in use for an extensive period of time in a real-use setting. By doing so our empirical study adds to the current body of research as reported in the literature in the areas of e.g. task interruption studies, workplace awareness studies, and empirical workplace studies with an attention, perceptual or cognitive task completion focus. It also adds to the current body of research which has mentioned, but not solely focused upon, the fact that it seems like that there is some kind of fine grained, implicit process going on that complements the more explicit availability management approach to e.g. turn the camera or audio channel off if being to busy to respond. We believe that the empirical case offered in this paper has shed some new light on this implicit availability management phenomenon and its relation to more explicit availability management approaches and the ambiguity in between.

Our results from the empirical study show that always-on media spaces allow for availability management through implicit cues, often transcended by the user from the physical world and how these cues, over time, support the development of a common ground of shared social conventions. This creation of a common ground is important in order to have a shared view of what these different signals communicate but also to allow for exceptions. These results were possible to extract from our longitudinal study and these results also confirm similar results from previous research conducted that has pointed in this direction based on more short-term and experimental studies (e.g. Lantz 1986, Gaver et al. 1992, Johnson and Greenberg 1999). 
We believe that if this shared understanding is established it also brings several positive side-effects including an increase of workplace awareness, a sense of group belonging, and maybe foremost a more natural and more 'face-to-face interaction'-like way of working together as a group in which availability is something highly dynamic, constantly changing, and highly situational. Something that is hard to cope with if only relying on explicit methods for regulating one's availability by constantly turning on and off different technical features, communication channels and availability/presence profiles.

In this paper we have further shown that the estimated availability of a colleague provides the individual with important information before selecting an appropriate communication channel for establishment of interaction. However, decisions of how to approach a colleague are not solely based upon an estimation of the availability of a colleague, but also upon other factors such as the nature of the errand and the knowledge of a person that is something that is acquired due to longitudinal virtual and physical co-existence. These are all aspects that enable individuals to deal with the ambiguity of availability cues and prevent misinterpretation and promote a smooth flow of communication.

In this paper we have also shown that the decision of how to approach a colleague based upon estimated availability is often a decision of 'how', and not a decision of 'if'. This is an indication that points towards a situation in which interruptions are not hindered, but rather that their disruptive effects are reduced. It also points towards a situation in which knowledge of person, generated after longitudinal virtual and physical co-existence, enables the development of an understanding concerning the communicational preferences of others in combination with an understanding of how to interpret the availability of a certain colleague in a given situation.

In our study of the online media space Marratech Pro we have arrived at a few implications for design of media spaces in support of implicit availability management.

First of all, we believe that it is important to design media spaces for always-on sessions as to reduce overhead work related to initiating multi-party interaction. In order to prevent a situation in which the actual system itself increases the amount of interruption for the individual the participation in the virtual environment and the management of the system should be as lightweight as possible.

Second, we think that it is necessary in design of always-on media spaces to allow for availability management through implicit cues, often transcended by the user from the physical world and to, over time, support the development of a common ground of shared social conventions in order to have a shared view of what these different signals communicates but also to accept exceptions. This is further emphasized by the fact that the relation between implicit and explicit availability management is, according to our results, characterized by an ambiguity, which calls for translation efforts from the individual. This translation process is dependent of an extensive knowledge of person in combination with awareness created through unforced gathering of synchronous and asynchronous information about the whereabouts of others, since the behaviour of one's colleagues has to be translated accordingly before estimating their availability. An ongoing long-lasting co-existence in a virtual environment prevents a situation in which individuals become lost in translation and cause counterproductive interruptions for others. The development of a common ground in the virtual room is highly dependent upon an extended virtual co-existence. While this might not be a straightforward technical design implication we still think that this issue is important to stress as to avoid design of media spaces that only rely on techniques for explicit availability management. The question of designing for explicit versus implicit availability management is on a more philosophical level related to the fundamental question of whether we should strive for machine interpretation or human interpretation of availability status. While many of the explicit techniques reviewed in this paper rely on machine-based interpretations of human availability we strongly believe that the role of the machine should be to provide the user with information that could help him or her to better interpret another person's availability status. However, the decision of whether or not to interrupt someone based on this interpretation should always be left to the human. This, to ensure that humans are always in charge of managing their social relations, although these relations are sometimes mediated via machines, and also attributed to the highly situated nature of peoples availability (Wiberg and Whittaker 2005, Whittaker, 2005).

Finally, we acknowledge that individuals sometimes might become lost in translation and interpret availability cues in a wrong way, even in situations of long lasting virtual and physical co-existence, especially if the awareness information received from others is limited. This is something that could be prevented by system generated awareness information. However, we strongly believe that regulating availability on a social level instead of on a solely technical level has the advantage of better coping with the highly situated, multitasking, multithreaded and everchanging dynamic of modern group works.

\section{Acknowledgements}

Thanks are due to Professor Victor Kaptelinin for valuable comments on earlier versions of this paper. Thanks are also due to the anonymous reviewers for their critical comments and constructive suggestions. 


\section{References}

Abel, M., 1990, Experiences in an exploratory distributed organization. In Intellectual Teamwork: Social Foundations of Cooperative Work, J. Galegher, R.E. Kraut and C. Egido (Eds), pp. 489-510 (New Jersey: Lawrence Erlbaum Associates).

AdamcZyK, P.D. and Bailey, B.P., 2004, If not now, when?: The effects of interruption at different moments within task execution. In Proceedings of the SIGCHI conference on Human factors in computing systems, 24-29 April 2004, Vienna, Austria, pp. 271-278 (New York: ACM Press)

Argyle, M., 1988, Bodily communication (London: Methuen \& Co).

Baecker, R.M., Grudin, J., Buxton, W.A.S. and Greenberg, S., 1995, Human-computer interaction: toward the year 2000 (San Francisco: Morgan Kaufmann Publishers).

Begole, J., Matsakis, N.E. and Tang, J.C., 2004, Lilsys: Sensing unavailability. In Proceedings of the 2004 ACM conference on Computer supported cooperative work, 6-10 November 2004, Chicago, Illinois, pp. 511-514 (New York: ACM Press).

Benford, S., Bowers, J., Fahlén, L.E. and Greenhalgh, C., 1994, Managing mutual awareness in collaborative virtual environments. In Proceedings of ACM SIGCHI conference on Virtual reality and technology (VRST'94), 23-26 August 1994, Singapore pp. 223-226 (New York: ACM Press).

Beyer, H. and Holtzblatt, K., 1998, Contextual Design: Defining Customer-Centered Systems (San Fransisco: Morgan Kaufmann Publishers).

Bly, S.A., Harrison, S.R. and Irwin, S., 1993, Media spaces: bringing people together in a video, audio, and computing environment. Communications of the ACM, 36, pp. 28-47.

Bly, S. and Anderson, S., 1996, CSCW and the Internet. ACM SIGOIS Bulletin, 17, pp. 10-24.

Burmistrov, I. and Leonova, A., 1997, Interruptions in the computer aided office work: Implications to user interface design. In From Experience to Innovation, P. Seppälä, T. Luopajärvi, C.-H. Nygård and M. Mattila (Eds),: Proceedings of the 13th Triennial Congress of the International Ergonomics Association, Vol. 5, Helsinki: Finnish Institute of Occupational Health, pp. $77-79$.

Buxton, W., 1997, Living in augmented reality: Ubiquitous media and reactive environments. In Video Mediated Communication, K. Finn, A. Sellen and S. Wilber (Eds), pp. 363-384 (Hillsdale, N.J, Erlbaum). An earlier version of this chapter also appears in Proceedings of Imagina '95, pp. 215-229.

Buxton, B. and Moran, T., 1990, EuroPARC's integrated interactive intermedia facility (IIIF): early experiences. In Proceedings of the IFIP WG 8.4 confernece on Multi-user interfaces and applications, 1990, Heraklion, Crete, pp. 11-34 (Amsterdam: Elsevier North-Holland, Inc).

Cockburn, A. and GreenberG, S., 1993, Making contact: getting the group communicating with groupware. In Proceedings of the ACM COCS'93 Conference on Organizational Computing Systems, 1-4 November 1993, Milpitas, CA, pp. 31-41 (New York: ACM Press).

Cohen, J., 1993, 'Kirk Here:' Using genre sounds to monitor background activity. In Proceedings of InterCHI'93 Conference on Human Factors in Computing Systems, April 1993, pp. 63-64 (New York: ACM Press).

Cutrell, E., Czerwinski, M. and Horvitz, E., 2001, Notifications, disruption, and memory: Effects of messaging interruptions on memory and performance. In Proceedings of Interact 2001: IFIP Conference on Human-Computer Interaction, July 2001, Tokyo, Japan, pp. 263-269 (Amsterdam: IOS Press).

Czerwinski, M., Cutrell, E. and Horvitz, E., 2000a, Instant messaging and interruption: Influence of task type on performance. In Proceedings of OZCHI 2000: Interfacing Reality in the New Millennium, Sydney, Australia, pp. 356-361 (New York: Academic Press).
Czerwinski, M., Cutrell, E. and Horvitz, E., 2000b, Instant messaging: effects of relevance and time. In People and Computers XIV: Proceedings of HCI 2000, S. Turner and P. Turner (Eds), Vol. 2, pp. 71-76 (Swindon: British Computer Society).

Davenport, T.H. and Beck, J.C., 2001, The Attention Economy: Understanding the New Currency of Business (Boston: Harvard Business School Press).

Dix, A. and Beale, R. (Eds), 1996, Remote cooperation: CSCW issues for mobile and teleworkers (London: Springer-Verlag).

Dourish, P. and Belotti, V., 1992, Awareness and coordination in shared workspaces. In Proceedings of the 1992 ACM Conference on ComputerSupported Cooperative Work, 1-4 November 1992, pp. 107-114 (New York: ACM Press).

Dourish, P. and BLY, S., 1992, Portholes: supporting awareness in a distributed work group. In CHI'92 Conference Proceedings: $A C M$ Conference on Human Factors in Computing Systems, P. Bauersfeld, J. Bennett, and G. Lynch (Eds), 3-7 May 1992, Monterey, California, pp. 541-547 (New York: ACM Press).

ENDLER, M., 1996, Availability management of distributed programs and services. In Proceedings of the 1996 conference of the Centre for Advanced Studies on Collaborative research, 12-14 November 1996, Toronto, Ontario, Canada, p. 9.

Erickson, T., Halverson, C., Kellog, W.A., Laff, M. and Wolf, T., 2002, Supporting community and building social capital: Social translucence: designing social infrastructures that make collective activity visible. Communications of the ACM, 45, pp. 40-44.

FARHoOmand, A.F. and DruRY, D.H., 2002, Managerial information overload. Communications of the ACM, 45, pp. 127-131.

Fish, R.S., Kraut, R.E. and Chalfonte, B.L., 1990, The VideoWindow system in informal communication. In Proceedings of the 1990 ACM conference on Computer-supported cooperative work, 7-10 October 1990, Los Angeles, California, United States, pp. 1 - 11 (New York: ACM Press).

Fish, R.S., Kraut, R.E., Root, R.W. and Rice, R.E., 1993, Evaluating video as a technology for informal communication. Communications of the ACM, 36, pp. 37-48.

Fogarty, J., Hudson, S.E. and LaI, J., 2004a, Examining the robustness of sensor-based statistical models of human interruptibility. In Proceedings of the SIGCHI conference on Human factors in computing systems, 24-29 April 2004, Vienna, Austria, pp. 207-214 (New York: ACM Press).

Fogarty, J., LaI, J. and Christensen, J., 2004b, Presence versus availability: The design and evaluation of a context-aware communication client. International Journal of Human-Computer Studies, 61, pp. 299-317.

Fogarty, J., Hudson, S.E., Atkeson, C.G., Avrahami, D., Forlizzi, J., Kiesler, S., Lee, J.C. and Yang, J., 2005, Predicting human interruptibility with sensors. ACM Transactions on Computer-Human Interaction (TOCHI), 12, pp. 119-146.

Fussel, S.R., Kraut, R.E., Lerch, F.J., Scherlis, W.L., McNally, M.M. and CADIZ, J.J., 1996, Coordination, overload and team performance: Effects of team communication strategies. In Proceedings of the 1998 ACM conference on Computer supported cooperative work, 14-18 November 1998, Seattle, Washington, United States, pp. 275-284 (New York: ACM Press).

Fussel, S.R., Setlock, L.D. and Kraut, R.E., 2003, Effects of headmounted and scene-oriented video systems on remote collaboration on physical tasks. In Proceedings of CHI 2003, 5-10 April 2003, Ft. Lauderdale, Florida, pp. 513-520 (New York: ACM Press).

Gaver, W.W., 1991, Sound support for collaboration. In Proceedings of the Second European Conference on Computer Supported Cooperative Work ECSCW '91, 24-27 September 1991, Amsterdam, pp. 293-308 (Dordrecht: Kluwer).

GAVER, W.W., 1992, The affordances of media spaces for collaboration. In Proceedings of the 1992 ACM conference on Computer-supported cooperative work, 1-4 November 1992, Toronto, Ontario, pp. 17-24 (New York: ACM Press). 
Gaver, W.W., Moran, T., Maclean, A., Lövstrand, L., Dourish, P., Carter, K. and Buxton, W., 1992, Realizing a video environment: EuroPARC's RAVE system. In Proceedings of the SIGCHI conference on Human factors in computing systems, 3-7 May 1992, Monterey, California, pp. 27-35 (New York: ACM Press).

Gergle, D., Millen, D.E., Kraut, R.E. and Fussel, S.R., 2004a, Persistence matters: Making the most of chat in tightly-coupled work. In Proceedings of the SIGCHI CONFERENCE ON human factors in computing systems, 24-29 April 2004, Vienna, pp. 413-438 (New York: ACM Press).

Gergle, D., Kraut, R.E. and Fussel, S.R., 2004b, Gesturing, moving and talking together: Action as language in a shared visual space. In Proceedings of the 2004 ACM conference on Computer supported cooperative work, 6-10 November 2004, Chicago, Illinois, pp. 487-496 (New York: ACM Press).

Goebbels, G., Lalioti, V. and Göbel, M., 2003, Human factors in collaborative virtual environment: Design and evaluation of team work in distributed collaborative virtual environments. In Proceedings of the ACM symposium on Virtual reality software and technology, 1-3 October 2003, Osaka, pp. 231-238 (New York: ACM Press).

GonzÁlez, V.M. and MARK, G., 2004, "Constant, constant, multi-tasking craziness": Managing multiple working spheres. In Proceedings of the SIGCHI conference on Human factors in computing systems, 24-29 April 2004, Vienna, pp. 113-120 (New York: ACM Press).

Greenberg, S., 1996, Peepholes: Low cost awareness of one's community. In Conference companion on Human factors in computing systems: common ground, 13-18 April 1996, Vancouver, BC, pp. 206-207 (New York: ACM Press).

Gutwin, C., Roseman, M. and Greenberg, S., 1996, A usability study of awareness widgets in a shared workspace groupware system. In Proceedings of the 1996 ACM conference on Computer supported cooperative work, 16-20 November 1996, Cambridge MA, pp. 258-267 (New York: ACM Press).

Gutwin, C., 1997, Workspace awareness in real-time distributed groupware. $\mathrm{PhD}$ thesis, Department of Computer Science, University of Calgary.

Gutwin, C. and Greenberg, S., 1999, The effects of workspace awareness support on the usability of real-time distributed groupware. $A C M$ Transactions on Computer-Human Interaction, 6, pp. 243-281.

Gutwin, C. and Greenberg, S., 2002, A descriptive framework of workspace awareness for real-time groupware. Computer Supported Cooperative Work, 11, pp. 411-446.

Handel, M. and Herbsleb, J.D., 2002, I M everywhere: What is chat doing in the workplace? In Proceedings of the 2002 ACM conference on Computer supported cooperative work, 16-20 November 2002, New Orleans, Louisiana, pp. 1-10 (New York: ACM Press).

Heath, C. and Luff, P., 1991, Disembodied conduct: Communication through video in a multimedia environment. In Proceedings of the SIGCHI conference on Human factors in computing systems: Reaching through technology, 27 April-2 May 1991, New Orleans, Lousiana, pp. 99-103 (New York: ACM Press).

Hollan, J., Hutchins, E. and Kirsh, D., 2000, Distributed cognition: Toward a new foundation for human-computer interaction research. ACM Transactions on Computer-Human Interaction, 7, pp. 174- 196.

Horwitz, E. and Apacible, J., 2003, Learning and reasoning about interruption. In Proceedings of the 5th international conference on Multimodal interfaces ICMI '03, 5-7 November 2003, Vancouver, British Columbia, pp. 20-27 (New York: ACM Press).

Hudson, J., Christensen, J., Kellog, W.A. and Erickson, T., 2002, Structure and flow: "I'd be overwhelmed, but it's just one more thing to do:" Availability and interruption in research management. In Proceedings of the SIGCHI conference on Human factors in computing systems: Changing our world, changing ourselves, 20-25 April 2002, Minneapolis, Minnesota, pp. 97-104 (New York: ACM Press).
Hudson, S., Fogarty, J., Atkeson, C., Avrahami, D., Forlizzi, J., Kiesler, S., LeE, J. and YANG, J., 2003, Modeling user behaviour: Predicting human interruptibility with sensors: A Wizard of Oz feasibility study. In Proceedings of the SIGCHI conference on Human factors in computing systems, 5-10 April 2003, Ft. Lauderdale, Florida, pp. 257-264 (New York: ACM Press).

ICQ INC., 1996-2006, ICQ ${ }^{\circledR}$, internet messaging services.

IsaAcs, E., Walendowski, A. and Rangathan, D., 2002, I Think, therefore IM: Hubbub: a sound-enhanced mobile instant messenger that supports awareness and opportunistic interactions. In Proceedings of the SIGCHI conference on Human factors in computing systems: Changing our world, changing ourselves, 20-25 April 2002, Minneapolis, Minnesota, pp. 179-186 (New York: ACM Press).

Johnson, B. and GreenberG, S., 1999, Judging people's availability for interaction from video snapshots. In Proceedings of the Thirty-Second Annual Hawaii International Conference on System Sciences - Volume 1, 5-8 January 1999, Hawaii, p. 1026 (Washington: IEEE Computer Society).

Kakihara, M., Sørensen, C. and Wiberg, M., 2004, Fluid Interaction in Mobile Work Practices. In The Interaction Society: Practice, Theories and Supportive Technologies, M. Wiberg (Ed.), pp. 171-193 (Hershey PA: Idea Group).

Kraut, R.E., Egido, C. and Galegher, J., 1988, Patterns of contact and communication in scientific research collaborations. In Proceedings of the 1988 ACM conference on computer-supported cooperative work, 26-28 September 1988, Portland, Oregon, pp. 1-12 (New York: ACM Press).

Kraut, R.E., Fussel, S.R. and Siegel, J., 2003, Visual information as a conversational resource in collaborative physical tasks. HumanComputer Interaction, 18, pp. 13-49.

Kristoffersen, S., 1997, MEDIATE: Video as a first-order datatype. Proceedings of the International ACM SIGGROUP Conference on Supporting Group Work: The Integration Challenge, 16-19 November 1997, Phoenix, Arizona, pp. 395-404 (New York: ACM Press).

Kristoffersen, S. and Ljungberg, F., 1999, An empirical study of how people establish interaction: implications for CSCW session management models. In Proceedings of the CHI 99 Conference on Human factors in Computing Systems: the CHI is the Limit, 15-20 May 1999, Pittsburgh, Pennsylvania, pp. 1-8 (New York: ACM Press).

Lai, J.S., Yoshihama, T., Bridgman, M., Podlaseck, P., Chou, P. and Wong, D., 2003, MyTeam: availability awareness through the use of sensor data. In Proceedings of Ninth IFIP TC13 International Conference on Human-Computer Interaction (Interact 2003), 1-5 September 2003, Zurich, pp. 503-510 (Amsterdam: IOS Press).

LANTZ, K.A., 1986, An experiment in integrated multimedia conferencing. In Proceedings of the 1986 ACM conference on Computer-Supported Cooperative Work, 3-5 December 1986, Austin, pp. 267-275 (New York: ACM Press).

Lauwers, J.C. and Lantz, K.A., 1990, Collaboration awareness in support of collaboration transparency: requirements for the next generation of shared window systems. In Proceedings of the SIGCHI Conference on Human Factors in Computing Systems: Empowering People, 1-5 April 1990, Seattle, Washington, pp. 303-311 (New York: ACM Press).

Lee, A., Schlueter, K. and Girgensohn, A., 1997, NYNEX Portholes: Initial user reactions and redesign implications. In Proceedings of the International ACM SIGGROUP Conference on Supporting group work: the Integration Challenge, 16-19 November 1997, Phoenix, Arizona, pp. 385-394 (New York: ACM Press).

LJUNGBerg, F., 1996, An initial exploration of communication overflow. In Proceedings of the International Conference on the Design of Cooperative Systems, Sophia Antipolis, 12-14 June 1996, Juan-Les-Pins, pp. 19-36 (Rocquencourt: INRIA Press).

Ljungberg, F., 1997, Networking. PhD thesis, University of Gothenburg. LJUNGBERG, F., 1999, Exploring CSCW mechanisms to realize constant accessibility without inappropriate interaction. Scandinavian Journal of Information Systems (SJIS), 11, pp. 115-136. 
Luungberg, F. and Sörensen, C., 1996, Communication deficiency and switching mechanisms. In Proceedings of 4th European Conference on Information Systems (ECIS'96), Lisbon, Portugal, J.D. Coelho et al. (Eds), Ficha Técnica, Vol. 2, pp. 1113-1119.

Ljungberg, F. and Sörensen, C., 2000, Overload: from transaction to interaction. In Planet Internet, K. Braa (Ed), pp. 113-136 (Lund, Sweden: Studentlitteratur).

Lövestrand, L., 1991, Being selectively aware with the Khronika System. In Proceedings of ECSCW'91 European Conference on Computer Supported Cooperative Work, 24-27 September 1991, Amsterdam, pp. 265-278 (Dordrecht: Kluwer Academic Publishers).

MACKAY, W.E., 1999, Media Spaces: Environments for Informal Multimedia Interaction. In Computer Supported Cooperative Work, M. Beaudouin-Lafon (Ed.), pp. 55-82 (Chichester: John Wiley).

Mantei, M., Baecker, R., Sellen, A., Buxton, W., Milligan, T. and Wellman, B., 1991, Experiences in the use of a media space. In Proceedings of the SIGCHI Conference on Human factors in Computing Systems: Reaching through Technology, 27 April-2 May 1991, New Orleans, Louisiana, pp. 203-208 (New York: ACM Press).

Markels, A., 1997, Memo 4/8/97, FYI: Messages inundate offices. Wall Street Journal, 8 April 1997, B1-8.

Milewski, A.E. and Smith, T.M., 2000, Providing presence cues to telephone users. In Proceedings of the 2000 ACM Conference on Computer Supported Cooperative Work, 2000, Philadelphia, Pennsylvania, pp. 89-96 (New York: ACM Press).

Nardi, B.A., Whittaker, S. and Bradner, E., 2000, Interaction and outeraction: instant messaging in action. In Proceedings of the 2000 ACM conference on Computer supported cooperative work, 2000, Philadelphia, Pennsylvania, pp. 79-88 (New York: ACM Press).

Norman, D. and DunaefF, T., 1993, Things that make us Smart: Defending Human Attributes in the Age of the Machine (Cambridge MA: Perseus Publishing).

O'Connail, B. and Frohlich, D., 1995, Timespace in the workplace: dealing with interruptions. In Conference companion on Human Factors in Computing Systems, 7-11 May 1995, Denver, Colorado, pp. 262-263 (New York: ACM Press).

Parviainen, R. and Parnes, P., 2004, A web based history tool for multicast e-meeting sessions. In Proceedings of the IEEE International Conference on Multimedia and Expo (ICME'2004), 27-30 June 2004, Taipei, Taiwan, pp. $511-514$ (New York: IEEE).

Perlow, L.A., 1999, The time famine: toward a sociology of work time. Administrative Science Quarterly, March, pp. 57-81.

Rodenstein, R., Abowd, G. and Catrambone, R., 1999, OwnTime: A system for timespace management. In Conference on Human Factors in Computing Systems. CHI'99 Extended Abstracts on Human Factors in Computing Systems, 15-20 May 1999, Pittsburgh, PA, pp. 200-201 (New York: ACM Press).

Rоoт, R.W., 1988, Design of a multi-media vehicle for social browsing. In Proceedings of the 1988 ACM Conference on Computer-Supported Cooperative Work, 26-28 September 1988, Portland, Oregon, pp. 25-38 (New York: ACM Press).

Rouncefield, M., Hughes, J.A., Rodden, T. and Viller, S., 1994, Working with "constant interruption": CSCW and the small office. In Proceedings of the 1994 ACM Conference on Computer Supported Cooperative Work, 22-26 October 1994, Chapel Hill, NC, pp. 275-286 (New York: ACM Press).
Rutkowski, A.-F., Vogel, D., Bemelmans, T.M.A. and Genuchten, M., 2002, Group support systems and virtual collaboration: The HKNET project. Group Decision and Negotiation, 11(2), 101-125.

Schmidt, K., 1994, Modes and mechanisms of interaction in cooperative work. Available online at: http://www.cti.dtu.dk/projects/cscw/ CSCW publ.html (accessed 22 June 2005).

Speier, C., Valacich, J.S. and Vessey, I., 1997, The effects of task interruption and information presentation on individual decision-making. In Proceedings of the Eighteenth International Conference on Information Systems, 14-17 December 1997, Atlanta, Georgia, pp. 21-36 (Atlanta: Association for Information Systems).

TANG, J.C. and RuA, M., 1994, Montage: Providing teleproximity for distributed groups. In Proceedings of the SIGCHI Conference on Human factors in computing Systems: Celebrating Interdependence, 24-28 April 1994, Boston, MA, pp. 37-43 (New York: ACM Press).

TANG, J.C., IsAaCs, E. and RuA, M., 1994, Supporting distributed groups with a montage of lightweight interactions. In Proceedings of the 1994 ACM Conference on Computer Supported Cooperative Work, 22-26 October 1994, Chapel Hill, North Carolina, pp. 23-34 (New York: ACM Press).

Tang, J.C., Yankelovich, N., Begole, J., Van Kleek, M., Li, F. and Bhalodia, J., 2001, ConNexus to awarenex: extending awareness to mobile users. In Proceedings of the SIGCHI Conference on Human factors in Computing Systems, March 2001, Seattle, Washington, pp. 221-228 (New York: ACM Press).

Want, R., Hopper, A., Falcão, V. and Gibbons, J., 1992, The active badge location system. ACM Transactions on Information Systems, 10, pp. $91-102$.

WAX, T., 1996, Red light, green light: Using peripheral awareness of availability to improve the timing of spontaneous communication. In Proceedings of CSCW'96 Conference on Computer Supported Cooperative Work (Short papers), Boston (New York: ACM Press).

WeICK, K., 1995, Sensemaking in Organizations (Thousand Oaks, CA: Sage).

Whittaker, S., Frohlich, D. and Daly-Jones, O., 1994, Informal workplace communication: What is it like and how might we support it? In Proceedings of the SIGCHI Conference on Human factors in computing Systems: Celebrating Interdependence, 24-28 April 1994, Boston, Massachusetts, pp. 113-137 (New York: ACM Press).

Whittaker, S., Jones, Q., Nardi, B., Creech, M., Terveen, L., Isaacs, E. and Hainsworth, J., 2004, ContactMap: organizing communication in a social desktop. ACM Transactions on Computer-Human Interaction, 11, pp. $445-471$.

WiberG, M., 2002, Interaction, interruptions, and lightweight support for availability management: A pre-study of issues related to the fluidity of work in the interaction society. Working paper 02.03, Department of Informatics, Umeå University, Sweden.

Wiberg, M. and WhittaKer, S., 2005, Managing availability: supporting lightweight negotiations to handle interruptions. ACM Transactions of Computer-Human Interaction (ToCHI), 12, pp. 356-387. 